\title{
Developing Scientific Thinking Through Inquiry Learning
}

\author{
Ika Andrini Farida, Dewi Retno Suminar, Nur Ainy Fardhana Nawangsari \\ Department of Psychology \\ Airlangga University \\ Surabaya, Indonesia \\ ika.andrini.farida-2014@psikologi.unair.ac.id
}

\begin{abstract}
Scientific thinking is defined as knowledge seeking. For knowledge to be acquired, students need to master inquiry skills, or the capability to design experiments and to obtain evidence. Inquiry learning facilitates students to develop scientific thinking. The researchers have different views of how to teach students inquiry skills, by direct instruction or discovery. Some researchers found that students in direct instruction group master inquiry skills are better than students in discovery group. The other researchers argue that in a long time, discovery learning will be more effective because it helps students to reach a metastrategic understanding so the students can transfer the knowledge to the other situations. The purpose of this literature review is to describe and discuss the results of empirical research of the effectiveness of these two approaches. This case is such an important topic because within inquiry learning, students have the opportunity to grow up as a scientifically literate person and to develop their critical thinking. Within Curriculum 2013 in Indonesia, inquiry learning has been emphasized for the learning processes in the elementary and middle schools. This study will be useful for teachers to consider how the best way is to foster the development of students' inquiry skills.
\end{abstract}

Keywords: scientific thinking, inquiry learning, literature review

\section{INTRODUCTION}

Students learn science concepts, facts, and theories in school, but the most important thing to learn is scientific thinking or scientific reasoning. There is a difference between learning science concepts and learning scientific thinking. Scientific thinking is defined as knowledge seeking [1], [2], so it is a process that is committed to acquire new knowledge (science as a process). One reason why it is significant for students to master this competency is because it is a kind of domain-general knowledge. Such knowledge is easily transferred to a new situation whenever is needed. Science concepts refer to the knowledge acquired through scientific thinking (science as a product) [3]. Thus, students need to learn science as a product as well as science as a process.

The second reason why scientific thinking is essential to learn is because it helps students to think critically. This is why the capacity to think scientifically is not just needed by scientists but by everyone in daily living. To think scientifically, students must coordinate theory or beliefs and evidence. They learn to understand that there is theory or beliefs (subjective aspect of knowing) and there is evidence (objective aspect of knowing). To determine whether a particular theory or belief is right or wrong, students will need to consider the evidence and argument supporting that belief. A theory or belief will be considered to be right if it is supported by an adequate evidence and argument [1]. Students become accustomed to think critically and not to accept some beliefs without first considering the evidence and argument.

One of the class activities that facilitate students to practice scientific thinking is inquiry learning. Kuhn, et al [4] defined inquiry learning as

$$
\begin{aligned}
& \text { an educational activity in which students } \\
& \text { individually or collectively investigate a set of } \\
& \text { phenomena-virtual or real-and draw } \\
& \text { conclusions about it. (pp. 496-497) }
\end{aligned}
$$

Inquiry learning has become the standard of science education in many countries, including in Indonesia. For students in Indonesia, inquiry learning has been emphasized as an approach of the learning process for elementary and middle school students. In curriculum 2013, inquiry learning comprises of five learning experiences, namely observing, questioning, experimenting, associating, and communicating [5]. Many textbooks for middle school students have provided inquiry tasksin almost every topic, especially in science subject.

Inquiry tasks have been widely used also by researchers who are interested in the development of scientific thinking or inductive reasoning. Researchers in developmental and cognitive psychology and in education have long been interested in scientific thinking to study how it develops and how to support students become competent to think scientifically. It was found that age and metacognition are among the critical factors that support students to think scientifically. Researchers also found that practice and instruction play important roles to help students to master inquiry skills. Teaching scientific thinking to students with 
practice is referred to as discovery approach, and teaching with instruction is known as direct instruction.

\section{A. Aims}

The purpose of this article is to present a review of studies concerned with how to foster students to master inquiry skills. This paper starts by describing the inquiry tasks used in school and in many research. Furthermore, we will present the research findings ofmetacognition roles in inquiry skills and then the different views of the best approach to teach students inquiry skills whether direct instruction or discovery learning. We finally discuss the cognitive processes involved in direct instruction and in discovery approach based on the information-processing theory and the implications of this study to the educational practices in Indonesia.

\section{METHODS}

The studies reviewed in this paper were obtained from reference lists on the previous reviews regarding the development of scientific thinking and teaching the control of variables strategy or inquiry skills [3], [6], [7]. This review examines 16 studies, published between 1975 and 2016, and consists of investigative and intervention studies. Investigative studies try to find correlation between inquiry skills and the other skills or individual differences. Intervention studies explore the effect of training or instruction on students performance in inquiry tasks.

\section{A. Inquiry Tasks}

Chinn and Malhotra [8] analyzed 26 inquiry tasks that were developed by researchers and 468 tasks that are available in the textbook of upper elementary and middle school students. There are five categories for inquiry tasks developed by the researchers, namely hands-on, computer simulated experimentation, database investigation, evidence evaluation tasks, and verbal design of research. Most of the inquiry tasks used in school are hands-on. Chinn and Malhotra [8] found that hands-on activities for middle-school and upper-elementary-school students fell into three categories, which are called simple experiments, simple observations, and simple illustrations. In simple experiments, students investigate the effect of a single independent variable on an outcome. In simple observations, students explore and describe objects. In simple illustrations, students commit a set of procedure and observe the outcome.

In hands-on inquiry tasks, students commit investigation with a real or physical material [8]. Klahr, et al. [9] for example, developed physical mousetrap cars for seventh and eighth-grade students. Students were asked to design a car that can travel farthest and conduct some experiments first to determine which features have the effect on the capacity of the car to travel. The features, related to car design, are bodies (short or long), front wheels (large thick, large thin, or small), back wheels (large thick, large thin, or small), and back axles (thin or thick). What has been learned by students from committing experiments was assessed using 8 multiple choice questions.
In computer simulated experimentation, students perform investigation using a computer program [8]. An example of computer simulated experimentation inquiry task was developed by [10]. Veenman and Spaans [10] used the term of inductive task referred to inquiry task. They developed biology domain inductive task of the plant-growing. The participants were asked to investigate how five features influence the height of plant growth by conducting a set of experiments. The features were giving water (once or twice a week), giving insecticide or not, putting dead leaves in the pot or not, placing the plant (indoors, on balcony, or in greenhouse), and size of the pot (large or small). The levels of plant growth were $5,10,15,20$, and $25 \mathrm{~cm}$ high. After conducting experiments, the participants gave their responses to 27 multiple choice questions about the effects of five features to the height of the plant growth.

If students design the experiment and collect the evidence in a computer simulated experimentation, in database investigation the students examine the evidence that has been collected or that is available. In evidence evaluation tasks, students are given written evidence and asked to make an inference. In verbal designs of research, students have not an opportunity to examine or interpret the evidence, they describe verbally how they design the experiments to examine a hypothesis.

\section{B. Measurement of Inquiry Skills}

Inquiry skill consists of two related skills, investigative and inferential skills. Investigative skill refers to designing experiments and generating evidence. Inferential skill is interpreting the obtained evidence [2]. Those two skills are also known as experimental design and evidence evaluation skill. There are some studies focusing on both investigative and inferential skill. Some other studies are focusing only on investigative or on inferential skill. Thus, the measurement of inquiry skills is conducted on each skill.

Investigative skill is measured based on a strategy used by students to manipulate and isolate variables. A student with investigative skill will use a valid strategy, known as control of variables strategy (COV) or vary one thing at a time (VOTAT), that is when he/she identifies the effect of an independent variable by making constant the effect of the other variables. The other strategies, hold one thing at a time (HOTAT) and change all, are considered as invalid strategies because they generate evidence that cannot be definitely interpreted [7].

The inference made from experimental evidence generally is classified into causal/non-causal and valid/invalid inferences. The student's inferential skill is measured from how many valid inferences that he/she makes either causal or non-causal. A student make a valid inference if he/she states that an independent variable that has an effect on an outcome as a causal variable, or that has not an effect on an outcome as a non-causal variable. On the contrary, invalid inferences are made if an independent variable that has an effect on an outcome is considered as a non-causal variable, or that has not an effect on an outcome as a causal variable. 


\section{RESULTS AND DISCUSSIONS}

\section{A. Metacognition Roles in Inquiry Skills}

Metacognition refers to knowledge and cognition of cognitive phenomena [11]. Metacognition belongs to higherorder cognition because it involves monitoring and control processes, different from cognition that refers to regular information processing [12]. Metacognition is such a complex phenomena that [13] proposed three components of metacognition, that is metacognitive knowledge, metacognitive experiences, and metacognitive skills. Two components of metacognition, metacognitive knowledge and metacognitive skills, have been found to play significant roles in inquiry skills. There are some studies that describe the roles of metacognition in inquiry skills.

Siegler and Liebert [14] gave a problem to fifth- and eighth-grade students how to make an electric train runs. The train can run if the students find out the particular configuration of four on/off buttons. The students were grouped into three conditions, conceptual framework, conceptual framework plus analogs, and control group. The students in conceptual framework group received brief instruction (20-25 minutes) about factors, levels, and tree diagram. The students in conceptual framework plus analogs group received the same instruction as the instruction for the students in conceptual framework group plus practice to represent all the possible solutions of the problem by using the tree diagram. The students in control group did not receive an instruction or practice. Paper and pencil were provided for the students to make a note of their findings. Siegler and Liebert [14] found that the students in groups that recieved instruction were more successful to solve the problem than students in control group. Eighth-grade students who made notes were also more successful to solve the problem than the fifth-grade students. It was assumed that the students who made notes have more metacognitive awareness or knowledge of the limitation of their memories to remember their findings. It was concluded that instruction, age, and metacognitive awareness play major roles in inquiry skills.

Veenman and Spaans [10] used inductive-learning task of the plant-growing to examine whether intelligence and metacognitive skills predict inquiry skills performance of seventh- and ninth-grade students. Veenman and Spaans [10] defined metacognitive skills as procedural knowledge that is needed to regulate and control learning processes, such as task analysis, planning, monitoring, checking, and reflection. Students were asked to find out how five independent variables with two or three levels affect the height of the plant growth by committing a set of experiments. It was found that metacognitive skills predict performance on inductive-learning task outweights intelligence.

The critical role of meta-level knowing procedural (metacognitive skills) and declarative (metacognitive knowledge) in scientific thinking has also been emphasized by [1], [15]. Meta-level knowing procedural selects strategies to meet task goal, manage and monitor its application. Feedback from the application of the strategies is turned back to meta-level. This feedback increases the awareness of the task goal and how it has been achieved by different strategies. The feedback also increases the awareness of the strength and weakness of the strategies. The awareness of meta-level supports students to find a correct strategy to meet the task goals. The role of meta-level knowing procedural underlie the discovery approach for students to achieve scientific thinking competence.

Meta-level knowing declarative has been studied with the title of epistemological understanding [16], [17]. Epistemological understanding is the basis of scientific thinking that consists of three understanding: (1) theoretical claim must be understood as a potentially wrong claim, (2) evidence must be understood as a tool to falsify a theoretical claim, and (3) theoretical claim and evidence must be understood as distinct epistemological categories. Students with mature epistemological understanding will be motivated to engage in inquiry activities because they understand that it is a way to acquire knowledge [1], [15].

Epistemological understanding is one the kind of metacognitive knowledge. The Another kind of metacognitive knowledge that play critical roles in scientific thinking as well is metacognitive understanding of the task objectives, strategies, and multivariable system. Kuhn and Pearsall [18] investigated the relation between metastrategic or metacognitive knowledge of the task objectives and strategies and performance in inductive causal reasoning tasks. They gave fifth-grade students two physical science problems (the boat and car problems) and two social science problems (the TV and school problems). The results showed that the performance improved whenever students have better metacognitive knowledge of task objectives and strategies.

The importance of metacognitive knowledge of task objectives in scientific thinking was also found by [19]. They investigated whether the valid inferences were influenced by learning condition. Participants in this study were 30 sixthgrade students. Twelve students were placed in experimental group, 18 students in control group, and additional 12 students in an alternative control group. The researchers used a computer simulation inquiry task of Earthquake Forecaster. The students were asked to investigate five variables (water pollution, water temperature, soil depth, soil type, and elevation) and make inferences whether the variables have or do not have an effect on the earthquake risk. The students in the experimental group had the opportunity to practice for some sessions and received a suggestion that they should focus on the effect of one variable. The students in the control group hade only one session working with the task. The students in the alternative control group had some sessions to practice like the students in the experimental group; they just did not receive the suggestion to focus on the effect of one variable. The results indicated that $75 \%$ of the students in the experimental group made two or three (of four possible) valid inferences, there was no student in the control group who made valid inferences, and $8 \%$ of the students in the alternative control group made valid inferences. It can be interpreted that practice alone does not help students to acquire the inquiry skills, but giving a suggestion to help students achieve 
metacognitive knowledge about task objectives is more important.

So far, the roles that metacognitive skills, metacognitive knowledge (about task objectives and strategies), and epistemological understanding play in scientific thinking have been discussed. Kuhn, et al. [20], [21] proposed that multivariable thinking is another capacity needed by students beyond the control of variables strategy to be competent to think scientifically. If the control of variables strategy is needed to design unconfounded experiments, multivariable thinking support students to make inferences. Multivariable thinking refers to the capacity to recognize that some variables could have contributed to an outcome [21].

\section{B. Different Views of Teaching Inquiry Skills}

The researchers have different views of how to teach students to master inquiry skills, by direct instruction or by discovery learning. In discovery learning, students by themselves try to find the correct strategy. There is no intervention from instructor except the direction of learning goals. There is no directing question and feedback for what students have done [22]. It takes some weeks for students to accomplish the inquiry task so that this approach receives critics because of the inefficiency.

The other researchers [23]-[25] have implemented the direct instruction to teach students inquiry skills. In this approach, the goals, material, examples, explanation, as well as the speed of learning, all are controlled by teacher or instructor. Students observe the instructor designing some experiments (confounded or unconfounded) so that they understand the effects of features on an outcome. For each experiment, the instructor ask the students whether they can make sure that a feature has or does not has an effect on an outcome. Then, the instructor explains why the unconfounded experiment can identify the feature that has an effect on an outcome and why the confounded experiment cannot.

Klahr and Nigam [24] investigated the effectiveness of direct instruction and discovery learning related to the acquisition of inquiry skills. The participants were third- and fourth-grade students that were placed randomly to direct instruction group or discovery learning group. The participants were asked to investigate how four variables (the steepness of the ramps, the surface of the ramps, the length of the downhill run, and the type of ball that rolls down the ramps) affected the distance that balls rolled through the downhill ramp. This study found that more students in direct instruction group acquired the ability to design unconfounded experiments than in discovery learning group. Moreover, it was found that students who achieved master (commit at least 3 from 4 unconfounded experiments) with direct instruction approach were as skilled as students who achieved master and expert with discovery approach in evaluating science poster task. This finding provides evidence that supports the path independent transfer hypothesis, that means if students achieve the mastery of a new procedure, the way they achieve that mastery will not affect their capability to transfer what they have learned.
Klahr and Nigam [24] postulated that this finding refused an opinion that learning transfer can occur only if students learn the skill with discovery approach.

Kuhn and Dean [19], [26] had different opinions about the findings of [24]. They argued that the advantage of discovery approach is that students can reach understanding at the metacognitive level. In discovery approach, students select by themselves the strategies that will be applied based on their understanding describing that by those strategies they will meet the objectives. Therefore, when students have discovered the correct strategy, they attain the understanding at the metacognitive level, why some strategies are right and why some other strategies are not right. Dean and Kuhn [26] argued that such metacognitive understanding cannot be reached in the direct instruction in which students are just instructed to use a strategy. The implication of attaining metacognitive understanding for students is that they can apply the skill they have learned at another task or situation, which is referred to as a long-term outcome. This long-term outcome, according to [26] was not reported by Klahr and Nigam [24].

\section{Inquiry Processes from Information-Processing Perspective}

The previous part of this paper has presented the different views of the right approach to teach students inquiry skills. This part presents an effort to understand the cognitive processes experienced by students when they are engaging in inquiry activities, and to explain which process that differentiates the direct instruction and discovery learning based on the information-processing perspective.

Information-processing is one of the cognitive models that was developed by cognitive psychologists. Cognitive psychology concerns with how people attend to and acquire information of the world, with how the information is stored and processed by the brain, and with how people solve problems, think, and formulate language [27].

A classical information-processing theory was proposed by Richard Atkinson and Richard Shiffrin in 1968, known as modal model. This model assumes that memory can be understood as a serial of different steps, in which the information is transferred from one storage to another. External stimuli initially enters the sensory memory, then transferred to short-term memory. The information in the short-term memory might lose or is passed to the long-term memory [28].

The cognitive psychologists realized that they need a more complex model to explain the people's brain. Alan Baddeley [29] and Graham Hitch examined some studies regarding the short-term memory and they argued that the main function of this memory is to hold some interrelated information so it can be processed and used. Baddeley [29] argued that short-term memory is not merely a passive storage but it performs a processing as well, so he preferred to use the term working memory than short-term memory [28]. 
Baddeley [29] assumed that working memory has four components namely phonological loop, visuospatial sketchpad, central executive, and episodic buffer. The phonological loop holds sound while the visuospatial sketchpad holds visual and spatial information and both holds information in limited amount and in a very brief time. The central executive performs planning and coordination but it does not store the information like the phonological loop and visuospatial sketchpad. The episodic buffer serves as temporary storage where the information from the phonological loop, visuospatial sketchpad, and long-term memory are combined. The episodic buffer actively manipulates the information allowing us to comprehend our experiences, to solve problems, and to plan subsequent activities.

According to information-processing theory, when students start to engage in inquiry task, the information related to the task (such as images, texts, or the voice of instructor) is received by the phonological loop and visuospatial sketchpad and then stored in the episodic buffer to be manipulated so the task can be accomplished. However, to be able to manipulate the information, the episodic buffer needs to retrieve the related knowledge that has been stored in the long-term memory. Kuhn and Pearsall [18], [26] found that performance on inductive causal reasoning task (inquiry task) increases when students have better metacognitive knowledge of task objectives and strategies. So, it can be assumed that this metacognitive knowledge (about task objectives and strategies) is what episodic buffer must retrieve from the long-term memory to be combined with the information related to the task recieved from the phonological loop and visuospatial sketchpad.

Once episodic buffer is managed to understand the inquiry task objectives and the right strategies to meet the objectives, another component of working memory, central executive, can make a plan of the steps to accomplish the inquiry task (such as focusing on the first independent variable, examining if the different levels of this variable have an effect to an outcome, continued with the second independent variable, and so on). In addition to making a plan, the central executive monitors the application of the strategy or the steps conducted during the task execution. Finally, the central executive evaluates whether the task objectives have been met or not. If the task objectives have not been met, the central executive will repeat again this cycle consisting of planning, monitoring, and evaluating until the task objectives are achieved.

The central executive is sometimes referred to as metacognition [30], [31], and more specificifically is referred to as metacognitive skill or meta-level knowing procedural. This far, it is clear that planning and monitoring served by the central executive or metacognitive skill are supported by the episodic buffer which is also supported by the metacognitive knowledge (about task objectives and strategies) retrieved from the long-term memory. This understanding will be usefull for describing the cognitive processes that occur in direct instruction and in discovery approach as well.
In direct instruction, the instructor explains or demonstrates how to design the unconfounded experiments before students engage in inquiry tasks. It can be understood based on the information-processing theory that students are taught metacognitive knowledge (about task objectives and strategies). Therefore, when students start to engage in inquiry task, that knowledge that have been taught to the students can be retrieved from a long-term memory, then it is easier for central executive or metacognitive skill to commit the planning and monitoring of the task execution.

In discovery approach, students are not taught metacognitive knowledge (about task objectives and strategies), so it is hard for the central executive or metacognitive skill to make a plan of the task execution because it is not supported by the related knowledge that can be retrieved from a long-term memory. Without the related knowledge, the central executive has to try to make a plan, monitor, and evaluate whether the task objectives have been met or have not. If the task objectives have not been met, the central executive has to repeat the cycle again and again. This is why the students need much longer time to accomplish the inquiry task with this approach.

It can be concluded that the difference between direct instruction and discovery approach, from the informationprocessing perspective, lies in the way students acquire metacognitive knowledge (about task objectives and strategies). In direct instruction, metacognitive knowledge is taught to students, but in discovery approach, students have to find out by themselves the task objectives and the correct strategies by engaging in the same inquiry task over and over.

\section{CONCLUSION}

This study has two important implications for educational practices in Indonesia particularly. The first implication is to help teachers acquire the understanding of what inquiry learning essentially is. This study will also be useful for teachers to consider how the best way is to foster the development of students' inquiry skills.

The most important mission of education is teaching students how to think and learn, so as adults they will be capable of acquiring whatever new knowledge and skill they need [32]. Inquiry learning is a way to reach that mission because it facilitates students how to think scientifically. Unfortunately, the term of inquiry learning seems like a fuzzy concept for most of the teachers and educational researchers in Indonesia. The meaning of inquiry learning has not been understood and its benefits have not been recognized. Therefore the implementation of inquiry learning does not generate increasing qualities of science education in Indonesia [33]. Inquiry tasks are available almost in every topic in many textbooks for students in Indonesia, but some tasks are skipped or just explained by teachers if they think it is too difficult to be done. This probably will not happen if the teachers recognize the benefits of inquiry learning. Thereby, the first principal thing to do is to support the teachers to have a clear understanding of what the meaning and benefits of inquiry learning are. 
From the information-processing perspective, we have a clearer understanding ofcognitive processes that students experience to acquire inquiry skills with direct instruction and discovery approach. It would be easier for teachers to teach inquiry skills to middle school students in Indonesia with direct instruction. Inquiry learning encompasses domain-general and domain-specific knowledge [3]. Inquiry skills that are taught to students are domain-general knowledge, that is how to design and interpret the unconfounded experiments. Once students master those skills, they can acquire a new knowledge in particular domain (domain-specific) independently.

The results of some studies regarding metacognitive knowledge of task objectives, strategies, and multivariable thinking that affect inquiry skills will be very useful for teachers. They will know exactly what must be taught to students before they engage in inquiry activities.

\section{REFERENCES}

[1] D. Kuhn, "What is scientific thinking and how does it develop?," in Handbook of Childhood Cognitive Development., Second edi., D. U. Goswami, Ed. Blackwell Publishing, 2010.

[2] D. Kuhn and S. Pearsall, "Developmental origins of scientific thinking.," J. Cogn. Dev., vol. 1, no. 1, pp. 113-129, 2000.

[3] C. Zimmerman, "The development of scientific reasoning skills," Dev. Rev., vol. 20, no. 1, pp. 99-149, 2000.

[4] D. Kuhn, J. Black, A. Keselman, and D. Kaplan, "The development of cognitive skills to support inquiry learning.," Cogn. Instr., vol. 18, no. 4, pp. 495-523, 2000 .

[5] Permendikbud, "Tentang Standar Proses Pendidikan Dasar dan Menengah," 65, 2013.

[6] M. Schwichow, S. Croker, C. Zimmerman, T. Höffler, and H. Härtig, "Teaching the control-of-variables strategy: A metaanalysis," Dev. Rev., vol. 39, pp. 37-63, 2016.

[7] C. Zimmerman, "The development of scientific thinking skills in elementary and middle school.," Dev. Rev., vol. 27, pp. 172-223, 2007.

[8] C. A. Chinn and B. A. Malhotra, Epistemologically Authentic Inquiry in Schools: A Theoretical Framework for Evaluating Inquiry Tasks. New York: Wiley Periodicals, Inc, 2002.

[9] D. Klahr, L. M. Triona, and C. Williams, "Hands on what? The relative effectiveness of physical versus virtual materials in an engineering design project by middle school children," J. Res. Sci. Teach., vol. 44, no. 1, pp. 183-203, 2007.

[10] M. V. Veenman and M. A. Spaans, "Relation between intellectual and metacognitive skills: Age and task differences," Learn. Individ. Differ., vol. 15, no. 2, pp. 159-176, 2005.

[11] J. H. Flavell, "Metacognition and cognitive monitoring: a new area of cognitive-developmental inquiry," Am. Psychol., vol. 34, no. 10, pp. 906-911, 1979 .

[12] E. Necka and J. Orzechowski, Cognition and Intelligence: Identifying the Mechanisms of the Mind., Higher-Ord. Cambridge University Press, 2005.
[13] A. Efklides, "Metacognition and affect: What can metacognitive experiences tell us about the learning process?," Educ. Res. Rev., vol. 1, no. 1, pp. 3-14, 2006.

[14] R. S. Siegler and R. M. Liebert, "Acquisition of formal scientific reasoning by 10 -and 13-year-olds: Designing a factorial experiment," Dev. Psychol., vol. 11, no. 3, pp. 401-402, 1975.

[15] D. Kuhn, "How do people know?," Psychol. Sci., vol. 12, no. 1, pp $1-8,2001$.

[16] D. Kuhn, R. Cheney, and M. Weinstock, "The development of epistemological understanding," Cogn. Dev., vol. 15, p. 309-328., 2000.

[17] D. Kuhn and S. Park, "Epistemological understanding and the development of intellectual values," Int. J. Educ. Res., vol. 43, no. 3, pp. 111-124, 2005.

[18] D. Kuhn and S. Pearsall, "Relations between metastrategic knowledge and strategic performance," Cogn. Dev., vol. 13, no. 2, pp. 227-247, 1998.

[19] D. Kuhn and D. Dean Jr., "Is developing scientific thinking all about learning to control variables?," Psychol. Sci., vol. 6, no. 11, pp. 866$870,2005$.

[20] D. Kuhn, K. Iordanou, M. Pease, and C. Wirkala, "Beyond control of variables: What needs to develop to achieve skilled scientific thinking?.," Cogn. Dev., vol. 23, no. 4, pp. 435-451, 2008.

[21] D. Kuhn, S. Ramsey, and T. S. Arvidsson, "Developing multivariable thinkers," Cogn. Dev., vol. 35, pp. 92-110, 2015.

[22] D. Kuhn, M. Garcia-Mila, A. Zohar, and C. Andersen, "Strategies of knowledge acquisition," Monogr. Soc. Res. Child Dev., vol. 60, pp. $1-128,1995$.

[23] Z. Chen and D. Klahr, "All other things being equal: Acquisition and transfer of the control of variables strategy," Child Dev., vol. 70, no. 5, pp. 1098-1120, 1999.

[24] D. Klahr and M. Nigam, "The equivalence of learning paths in early science instruction: Effects of direct instruction and discovery learning," Psychol. Sci., vol. 15, no. 10, pp. 661-667, 2004.

[25] M. Schwichow, C. Zimmerman, S. Croker, and H. Härtig, "Activities, What students learn from hands-on," J. Res. Sci. Teaching., 2016.

[26] D. Dean Jr and D. Kuhn, "Direct instruction vs. discovery: The long view," Sci. Educ., vol. 91, no. 3, pp. 384-397, 2007.

[27] R. Solso, No Title Cognitive Psychology, Sixth edit. Allyn and Bacon, 2001.

[28] M. W. Matlin, Cognition, Sixth edit. John Wiley \& Sons, Inc, 2005.

[29] A. Baddeley, "The episodic buffer: a new component of working memory?," Trends Cogn. Sci., vol. 4, no. 11, pp. 417-423, 2000.

[30] L. E. Berk, Child Development., Seventh ed. London: Pearson Education, Inc, 2006.

[31] D. F. Bjorklund, Children's Thinking: Cognitive Development and Individual Differences, Fourth edi. Wadsworth/Thomson Learning, 2005.

[32] D. Kuhn, "A developmental model of critical thinking.," Educ. Res., vol. 28, no. 2, pp. 16-46, 1999.

[33] N. Y. Rustaman, "Perkembangan Penelitian Pembelajaran Berbasis Inkuiri dalam Pendidikan Sains," in Seminar Nasional II Himpunan Ikatan Sarjana dan Pemerhati Pendidikan IPA Indonesia, 2005. 